\title{
Why Should We Be Pessimistic about Antirealists and Pessimists?
}

\begin{abstract}
The pessimistic induction over scientific theories (Poincaré, 1905/1952) holds that present theories will be overthrown as were past theories. The pessimistic induction over scientists (Stanford, 2006) holds that present scientists cannot conceive of future theories just as past scientists could not conceive of present theories. The pessimistic induction over realists (Wray, 2013) holds that present realists are wrong about present theories just as past realists were wrong about past theories. The pessimistic induction over antirealist theories (Park, 2014) holds that the latest antirealist explanation of the success of science (Lyons, 2003) has hidden problems just as its eight predecessors did. In this paper, I (i) criticize the pessimistic inductions over scientific theories, scientists, and realists, (ii) introduce a pessimistic induction over antirealist theories, and then (iii) construct two new pessimistic inductions. One is a pessimistic induction over antirealists according to which the author of the latest antirealist proposal cannot see hidden problems with his proposal just as his antirealist predecessors could not see hidden problems with their proposals. The other is the pessimistic induction over pessimists according to which since past pessimists have been wrong about their present scientific theories from the early $20^{\text {th }}$ century to the early $21^{\text {st }}$ century, future pessimists will also be wrong about their present scientific theories from the early $21^{\text {st }}$ century to the early $22^{\text {nd }}$ century.
\end{abstract}

\section{Keywords}

Historical Optimism, Pessimistic Induction, Scientific Antirealism, Scientific Realism

Park, Seungbae (2016). "Why Should We Be Pessimistic about Antirealists and Pessimists?" Foundations of Science. doi:10.1007/s10699-016-9490-y.

I am grateful to anonymous referees of this journal for insightful comments as well as to the participants of the third annual SoCal philosophy conference at San Diego State University in 2015.

Seungbae Park

nature@unist.ac.kr

http://nature.unist.ac.kr

Division of General Studies

Ulsan National Institute of Science and Technology

Ulsan, Ulju-gun 689-798

Republic of Korea

Seungbae Park is Associate Professor of Philosophy at Ulsan National Institute of Science and Technology in Republic of Korea. He received his Ph.D. from University of Arizona in 2001, having specialized in philosophy of science under the guidance of Prof. Richard Healey. He taught at University of Arizona, University of Maryland, and POSTECH before coming to his current institution in 2009.

\section{Introduction}

Henri Poincaré (1905/1952), P. Kyle Stanford (2006), K. Brad Wray (2013), and Seungbae Park (2014) run pessimistic inductions against different targets. Poincaré's pessimistic induction is against scientific theories, asserting that present theories will be overthrown as 
were past theories. Stanford's pessimistic induction is against scientists, claiming that present scientists cannot conceive of future theories just as past scientists could not conceive of present theories. Wray's pessimistic induction is against scientific realists, contending that present realists are wrong about present theories just as past realists were wrong about past theories. My pessimistic induction is against antirealist explanations of the success of science, maintaining that the latest antirealist proposal (Lyons, 2003) has hidden problems just like its eight predecessors.

In this paper, I (i) criticize the pessimistic inductions over scientific theories, scientists, and realists, (ii) introduce a pessimistic induction over antirealist theories, and then (iii) construct two new pessimistic inductions. One is a pessimistic induction over antirealists according to which the author of the latest antirealist proposal cannot see hidden problems with his proposal just as his antirealist predecessors could not see hidden problems with their proposals. The other is a pessimistic induction over pessimists according to which since Poincaré (1905/1952) and Mach (1911) were wrong about their present scientific theories, subsequent pessimists, such as Larry Laudan (1977), Hilary Putnam (1978), Stanford (2006), and Wray (2013), are also wrong about their present scientific theories, and future pessimists will also be wrong about their present theories. The aim of this paper is to show that we should be pessimistic about antirealists and pessimists.

I proceed as follows: In Section 2, I present the pessimistic induction over scientific theories and one of the realist objections to it. In Section 3, I introduce the pessimistic induction over scientists, which is constructed in response to the realist critique that present theories are more successful than past theories. I object that the premise of this pessimistic induction is false. In Section 4, I present the pessimistic induction over realists, which is also constructed in response to the realist objection that present theories are more successful than past theories. I also argue that the premise of this pessimistic induction is false. In Section 5, I introduce the pessimistic induction over antirealist theories and then reply to some possible objections to it. In Section 6, I transform the pessimistic induction over antirealist theories into a pessimistic induction over antirealists in order to counter a possible objection from antirealists that the latest antirealist proposal is better than its predecessors. Finally, in Section 7, I construct a pessimistic induction over pessimists.

Throughout this paper, 'antirealists' refers to those who embrace the antirealist explanations of the success of science. They are skeptical that realism best explains the success of science. 'Pessimists' refers to those who run the pessimistic inductions over scientific theories, scientists, and realists. They are pessimistic about scientific theories, scientists, and realists.

\section{The Pessimistic Induction over Theories}

Many philosophers of science (Worrall, 1989: 99; Kitcher 1993: 136; Psillos, 1999; Wray, 2013: 4321) regard the pessimistic induction over scientific theories as the strongest objection against scientific realism, the view that successful theories are (approximately) true. Poincaré formulates the pessimistic induction as follows:

The ephemeral nature of scientific theories takes by surprise the man of the world. Their brief period of prosperity ended, he sees them abandoned one after the other; he sees ruins piled upon ruins; he predicts that the theories in fashion today will in a short time succumb in their turn, and he concludes that they are absolutely in vain. (Poincaré, 1905/1952: 160)

Note that this pessimistic induction is composed of the premise that past theories were discarded and the conclusion that present theories will also be discarded. In this pessimistic 
induction, an inference is made from past theories to present theories. So it might be called the pessimistic induction over scientific theories. In order to justify the premise of the pessimistic induction over scientific theories, pessimists might appeal to Laudan's list of past theories:

\section{Laudan's List}

- the crystalline spheres of ancient and medieval astronomy;

- the humoral theory of medicine;

- the effluvial theory of static electricity;

- "catastrophist" geology, with its commitment to a universal (Noachian) deluge;

- the phlogiston theory of chemistry;

- the caloric theory of heat;

- the vibratory theory of heat;

- the vital force theories of physiology;

- the electromagnetic aether;

- the optical aether;

- the theory of circular inertia;

- theories of spontaneous generation. (Laudan, 1981:33)

After presenting the list of past theories, Laudan claims that "for every highly successful theory in the past of science which we now believe to be a genuinely referring theory, one could find half a dozen once successful theories which we now regard as substantially nonreferring" (1981: 35). If Laudan is right about the history of science, most successful past theories are false in the present light. This historical claim, if true, can serve as a strong premise of the pessimistic induction over scientific theories.

Realists have come up with various strategies to diffuse the pessimistic induction over scientific theories. Relevant to this paper is the one raised by Ludwig Fahrbach (2011a: 148), Seungbae Park (2011: 79), and Moti Mizrahi (2013: 3220). They argue that Laudan's list is not representative of the population of past theories. All the entries on the list are theories once accepted before the early $20^{\text {th }}$ century. In addition, the population of the theories from before the early $20^{\text {th }}$ century is far smaller than that of the theories from after the early $20^{\text {th }}$ century. Thus, a fair list representing the population of past theories would consist mostly of recent past theories and rarely of distant past theories, to use Fahrbach's (2011b: 1290) and Mizrahi's terms (2013: 3220). Distant past theories are such theories as the phlogiston theory of combustion, the caloric theory of heat, the miasma theory of diseases, and the ether theory of light. Recent past theories are such theories as the oxygen theory of combustion, the kinetic theory of heat, the germ theory of diseases, and the special theory of relativity. These theories are past theories from the perspective of the early $21^{\text {st }}$ century because they were in fashion in the early $20^{\text {th }}$ century, although they are also present theories from the perspective of the early $21^{\text {st }}$ century because they are still in fashion in the early $21^{\text {st }}$ century. Since Laudan's list consists only of distant past theories, a pessimistic induction based on it commits the fallacy of biased statistics.

The fallacy of biased statistics occurs when a sample for a general statement lacks variety. Consider, for example, the argument that $99 \%$ of people in this country believe that God exists because $99 \%$ of people in this church believe that God exists. The obvious flaw with this argument is that the members of the sample are composed only of people who attend a particular church. Such a sample is not representative of the population at large. We should select each member of the sample randomly from the collection of people in the entire country in order to ensure that the sample is fair. 
Similarly, pessimists should select each member of their sample randomly from the collection of distant past theories and recent past theories in order to ensure that the sample is fair. It is problematic to omit recent past theories, for they are dissimilar to distant past theories in the following two important respects. First, they have not been refuted. Second, they are more successful than distant past theories. Jarrett Leplin (1997: 141), Gerald Doppelt, (2007: 111), Juha Saatsi (2009: 358), Michael Devitt (2011: 292), Park (2011: 80), Fahrbach (2011b: 1290), and Mizrahi (2013) note that scientific theories have been becoming more successful. For these two reasons, it is not a negligible mistake to omit recent past theories.

Let me call Fahrbach, Park, and Mizrahi's observation of the history of science historical optimism. Historical optimism is composed of the theses that there are far more recent past theories than distant past theories, that the former are far more successful than the latter, and that the former have not been refuted, although the latter have. On the historical optimist account, most past theories are true in the light of present theories, and hence the history of science is not as gloomy as pessimists depict.

There are important implications of historical optimism. One of them is that the conclusion of the pessimistic induction over scientific theories is false. Recall that Poincare predicted in 1905 that then present theories, such as the germ theory of diseases, the kinetic theory of heat, and the special theory of relativity, would soon be rejected in short order. They, however, are still accepted in the early $21^{\text {st }}$ century. I will draw more disastrous implications of historical optimism in the next sections. Of course, they are disastrous from pessimists' point of view, but not from the realists' point of view.

\section{The Pessimistic Induction over Scientists}

Stanford (2006) grants that present theories are more successful than past theories, so we cannot extrapolate the fate of present theories from that of past theories. However, he attempts to get around the realist objection by constructing a pessimistic induction over scientists:

..we have, throughout the history of scientific inquiry and in virtually every scientific field, repeatedly occupied an epistemic position in which we could conceive of only one or a few theories that were well confirmed by the available evidence, while subsequent inquiry would routinely (if not invariably) reveal further, radically distinct alternatives as well confirmed by the previously available evidence as those we were inclined to accept on the strength of that evidence. (Stanford, 2006: 19)

Note that this pessimistic induction is not over scientific theories but over scientists. Stanford is saying that present scientists cannot conceive of certain alternatives, viz., future theories that will replace present theories, just as past scientists could not conceive of certain alternatives, viz., present theories that replaced past theories.

Stanford argues that the realist objection that present theories are more successful than past theories undercuts the pessimistic induction over scientific theories, but not his pessimistic induction, for his pessimistic induction is not over scientific theories but over scientists and there is no relevant cognitive difference between past and present scientists. Past and present scientists are similar in that they are all "creatures whose cognitive constitutions are not well suited to the task of exhausting the kinds of spaces of serious candidate theoretical explanations from which our scientific theories are drawn" (Stanford, 2006: 45). In other words, past and present scientists are all on the same unfortunate boat of being unable to conceive of their respective subsequent alternatives.

So far as I can tell, Stanford has made an important contribution to this debate. His pessimistic induction is more sophisticated than the pessimistic induction over scientific 
theories in that it appears to get around the realist objection that present theories are more successful than past theories. In addition, he has opened the door to a new debate between realists and pessimists by shifting the target of pessimistic induction from scientific theories to scientists. The new debate will cast light on the relationship between scientific theories and scientists.

Let me raise two objections against the pessimistic induction over scientists. First, the improvement of theories can be transferred to the improvement of scientists. As theories get better, so do scientists, who hold them in their minds. If you are knowledgeable about a subject matter, you are a better theorist than those who are ignorant about the subject matter. Since present scientists are more knowledgeable than past scientists, it is problematic to extrapolate the fate of present scientists from that of past scientists. An argument is required to show that the improvement of scientists does not make any difference, just as an argument was required to show that the improvement of scientific theories does not make any difference.

Second, like the pessimistic induction over scientific theories, the pessimistic induction over scientists falls prey to the thesis of historical optimism defended by Fahrbach, Park, and Mizrahi. Think about the premise of the pessimistic induction over scientists that past scientists could not conceive of their future theories, viz., our present theories. This premise is simply false. Recent past theories, such as the kinetic theory of heat and the special theory of relativity, were present theories from the perspective of past scientists of the early $20^{\text {th }}$ century. But they were also future theories from their perspective because they are still accepted in the early $21^{\text {st }}$ century. Thus, past scientists conceived of their future theories! ${ }^{1}$ Given that historical optimism asserts that there are far more recent past theories than distant past theories, we can say that past scientists conceived of most of their future theories. In short, Stanford's sentence quoted in the beginning of this section does not apply to the scientific inquiry of the recent past period.

\section{The Pessimistic Induction over Realists}

Like Stanford, Wray grants that present theories are more successful than past theories. He invites us, however, to imagine that our previous generation thought that their present theories were true although their past theories were false on the grounds that their present theories were more successful than their past theories. We now know in retrospect that their argument was erroneous. Wray states his argument as follow:

..the previous generation could construct a similar argument with respect to the generation that preceded them. They had instruments their predecessors could not fathom, and they achieved degrees of accuracy never achieved before. The pattern is clear. What looks like a brave new world to our predecessors does not look new to us. And similarly what looks new to us will not look so new to our offspring. (Wray, 2013: 4327)

In other words, imagine that realists existed in the past and that they thought that their present theories would not follow the path of their past theories on the grounds that the former were more successful than the latter. In retrospect, however, we now know that their present theories were abandoned just like their past theories. Similarly, present realists think that present theories will not be replaced by alternatives, even though past theories were, on the grounds that the former are more successful than the latter. In retrospect, however, our

\footnotetext{
1 'Present theory' and 'future theory' are temporal predicates referring to theories existing in different periods of time with respect to a certain point in time. Thus, present and future theories do not have to be distinct from one another, i.e., the same theories can be regarded as being both present and future theories.
} 
offspring will know that present realists are wrong, i.e., that our present theories will be ousted just like our past theories. In short, it is fallacious to reason that since a theory is more successful than its predecessor, it will remain stable unlike its predecessor. The history of science tells us that theories have been superseded by their successors even if they were more successful than their forerunners.

Like Stanford, Wray has made an important contribution to this debate. His pessimistic induction is distinct from both the pessimistic induction over scientific theories and the pessimistic induction over scientists. It is over realists, saying that present realists are wrong about our present theories, as past realists were wrong about their present theories. It is more sophisticated than the pessimistic induction over scientific theories in that it appears to invalidate the realist objection that present theories are more successful than past theories. In addition, Wray has opened the door to a new debate by shifting the target of pessimistic inductions from scientific theories to philosophers of science. The debate will throw light on the relationship between science and philosophy, as will become clear in the following section.

Like the pessimistic induction over scientists, however, the pessimistic induction over realists falls prey to historical optimism. Imagine that past realists of the early $20^{\text {th }}$ century were confident that their present theories were true, although their past theories were false, on the grounds that the former were more successful than the latter. So they believed that the oxygen theory, the kinetic theory, the germ theory, and the special theory of relativity were true, although the phlogiston theory, the caloric theory, the miasma theory, and the ether theory were false. We can now see in the early $21^{\text {st }}$ century that they were right! Thus, the premise of the pessimistic induction over realists that past realists were wrong about their present theories is false.

\section{The Pessimistic Induction over Antirealist Theories}

Recall that Wray constructs a pessimistic induction over realists. I welcome Wray's shifting of the target of pessimistic induction from scientific theories to philosophers of science. In this section, I introduce a pessimistic induction over antirealist theories of the success of science (Park, 2014) and then transform it into a pessimistic induction over antirealists. Given that antirealism is an alternative to realism, it should be able to withstand the criticisms similar to the ones leveled at realism. Otherwise, it cannot be a promising competitor to realism.

Philosophers have formulated antirealist explanations of the success of science to undermine the claim (Putnam, 1975; Psillos, 1999) that realism best explains the success of science, or to criticize the antirealist explanations that they think antirealists might be tempted to advocate. There are nine such antirealist proposals in the literature. They are advanced by Bas van Fraassen (1980: 40), Laudan (1984: 101), Arthur Fine (1986), Alan Musgrave (1988: 242), Fine (1991: 82), James Brown (1994), André Kukla (1996), Stanford (2000), and Timothy Lyons (2003: 900). In an earlier work, Park (2014) exposes problems with all of them except the latest one (Lyons, 2003) and then predict that the latest one would turn out to be problematic. In a nutshell, I construct the pessimistic induction over antirealist theories of the success of science. In the interest of saving space, I do not introduce every antirealist proposal here. Instead, I briefly introduce only Stanford's proposal (2000) and Lyons's proposal (2003) to illustrate how the pessimistic induction over antirealist theories works against Lyons's proposal.

Stanford suggests that a false theory is successful because it is predictively similarly to its corresponding true theory. For example, the Ptolemaic theory was successful because it was predictively similar to the Copernican theory. The two theories posited different 
structures of the universe but made similar predictions about the motions of planets, stars, the moon, and the sun. Elsewhere, Park (2003) objects that Stanford's proposal is conceptually flawed like the proposal that a tennis ball is spherical because it is similar to a baseball with respect to shape. We should rather say that the tennis ball is similar to the baseball with respect to shape because it is spherical. Analogously, we should rather say that a false theory is predictively similar to a true theory because it is successful. Stanford's proposal puts the cart before the horse.

Lyons suggests that a theory is successful because the "mechanisms postulated by the theory and its auxiliaries would, if actual, bring about all relevant phenomena thus far observed and some yet to be observed at time $t$; and these phenomena are brought about by actual mechanisms in the world" (2003: 900). In simple terms, a theory is successful because the world operates approximately as if it is true. There is a huge difference between Lyons's proposal and the proposal that a theory is successful because the world operates as the theory says it does. The former proposal involves the belief that the theory is merely (approximately) empirically adequate, whereas the latter involves the belief that the theory is true. So Lyons's proposal suits antirealists' need to explain the success of a theory without believing that it is true.

Without exposing any intrinsic problem with Lyons's proposal, Park (2014) rejects it on the grounds that its eight forerunners were problematic. Lyons's proposal has hidden problems and they will be exposed later:

It appears that Lyons's proposal does not have problems, but in reality it has, and they will be exposed in the future. Its eight forerunners were disclosed to be problematic, so it will also be unveiled to be problematic. (Park, 2014: 16)

Thus, Lyons's proposal was born problematic as a matter of induction. Of course, I was mimicking Stanford (2006), who did not expose any intrinsic problems with present scientific theories and yet predicted that they would be replaced by unconceived alternatives as were past theories.

How would antirealists reply to the pessimistic induction over antirealist theories? They might retort that antirealist theories are different from scientific theories in that the former are about science while the latter are about the world. The second-order theories and the first-order theories should be judged by different standards. Antirealist theories do not fall prey to a pessimistic induction, although scientific theories do.

In his earlier work, Park (2014: 17-19) anticipates the foregoing possible antirealist reply and raised several objections to it. I do not introduce them here in the interest of saving space. Let me add here the following two critical comments. First, the attempt to drive a wedge between antirealist theories and scientific theories should not sound agreeable to Wray (2013), who constructs a pessimistic induction over philosophers of science. Recall that on his account, past and present realists are on the same unfortunate boat of holding overconfident views about their present theories. So he would not have any problem with the pessimistic induction over antirealist theories.

Second, realists can accept the antirealist contention that antirealist theories and scientific theories should be judged by different standards. ${ }^{2}$ Realists, however, would impose opposite standards to antirealist theories and scientific theories, insisting that antirealist theories are vulnerable to a pessimistic induction but scientific theories are not. Thus, it is one thing to say that antirealist theories and scientific theories should be judged by different

\footnotetext{
${ }^{2}$ I am setting aside those realists who accept naturalism that there is no fundamental difference between philosophy and science.
} 
standards. It is another to say that antirealist theories are immune to a pessimistic induction while scientific theories are not. An argument is required to infer the latter from the former.

A possible objection against the pessimistic induction over antirealist theories is that the downfall of the eight antirealist proposals amounts at most to grounds for adopting the fallibilist attitude toward Lyons's proposal (referee). In other words, the downfall of the eight antirealist proposals constitutes a reason for believing that it is possible that Lyons's proposal is problematic, but it does not constitute a reason for believing that it is likely that Lyons's proposal is problematic. So it is wrong to reject Lyons's proposal on the grounds that its eight forerunners had hidden problems.

The pessimistic induction over antirealist theories, however, parallels the pessimistic induction over scientific theories. So if the downfall of eight antirealist proposals does not provide an inductive rationale for thinking that Lyons's proposal is problematic, the downfall of the twelve past theories on Laudan's list (1981: 33) or the downfall of all the past theories does not provide an inductive rationale for thinking that present theories will be thrown out. The downfall of past theories merely constitutes the reason for thinking that it is possible that present theories will be ousted. So it is wrong to predict that present theories will probably follow the course of past theories.

Another possible objection related to the preceding objection is that it is wrong to reject Lyons's proposal on the grounds that its eight predecessors are problematic (referee). Rejecting it requires engaging with the detail of Lyons's proposal and exposing specific problems with it. My previous paper (2014) and this paper, however, purposefully avoid engaging critically with the details of Lyons's view. Why is it that specific objections to Lyons's proposal are not necessary to discredit it?

Again, the pessimistic induction over antirealist theories mirrors the pessimistic induction over scientific theories. So if it is unfair to for me to reject Lyons's proposal without exposing intrinsic problems with it, it is also unfair for pessimists to reject present theories without exposing any intrinsic problems with them. For example, what exactly is wrong with the germ theory of diseases? Does it have an anomaly? If it has, what is it? Is it inconsistent with other theories? If so, state the other theories and explicate how it is inconsistent with them. Answering such questions should precede rejecting present theories.

Let me add that a pessimistic induction of any sort operates under the presupposition that an idea is problematic if its predecessor is problematic. Obviously, the referee rejects the presupposition when s/he requests that I should expose specific problems with Lyons's proposal instead of merely saying that it has eight problematic predecessors. The referee's intuition is agreeable. Going along with the intuition, however, means going against the strongest objection to realism.

Another possible objection to the pessimistic induction over antirealist theories is that the nine antirealist proposals are not intended to be explanations of the success of science but rather are intended to be philosophical analyses of what it is for scientific theories to be explanatory (referee). On this account, antirealists were engaged in philosophical analyses of what it means for scientific theories to be successful. Scientific theories and philosophical analyses are fundamentally different from each other. There might be infinitely many unconceived alternatives that compete with present scientific theories, but there might be finitely many unconceived analyses that compete with Lyons's analysis. In that case, antirealists will someday reach the unproblematic antirealist analysis, as they eliminate more and more problematic antirealist analyses from the possibility space of unconceived analyses. In contrast, scientists will never be able to reach true scientific theories no matter how large the number of scientific theories they may eliminate from the possibility space of unconceived alternatives is. 
Philosophers who put forward the nine antirealist explanations of the success of science, however, would disagree with the foregoing interpretation of what they were doing. They would argue that they were proposing theories about science, just as scientists propose theories about the world. After all, they were proposing antirealist alternatives to the realist explanation that theories are successful because they are (approximately) true, and Putnam took realism to be an "adequate scientific description of science and its relation to its objects" (1975: 73). He did not take his proposal to be a philosophical analysis of what it means for scientific theories to successful. Thus, if the nine antirealist proposals are philosophical analyses, they cannot be alternatives to the realist explanation and hence cannot undermine the realist claim that realism best explains the success of science. But the referee is right that the pessimistic induction against the antirealist theories is built upon Putnam's (1975) view and Quine's view (1969) that there is no fundamental difference between philosophy and science.

\section{The Pessimistic Induction over Antirealists}

Lyons might contend that although Stanford's proposal puts the cart before the horse, his proposal does not. There is no conceptual flaw with the suggestion that a theory is successful because the world operates approximately as if it is true. So even if Stanford's proposal had a hidden problem, his proposal does not. This possible reply from Lyons parallels the realist contention that present theories are more successful than past theories. So even if past theories were ousted, present theories will not.

This possible reply from Lyons, however, is subject to an objection similar to the one that Stanford raises against realists. In Stanford's spirit, we can transform the pessimistic induction over antirealist theories into a pessimistic induction over antirealists according to which Lyons cannot see hidden problems with his proposal, as his antirealist predecessors could not see hidden problems with their proposals. There is no relevant cognitive difference between Lyons and his predecessors in seeing hidden problems. All of their cognitive constitutions are not well suited to the task of seeing hidden problems with their proposals that are fated to be revealed in a subsequent inquiry.

In addition, we can construct a pessimistic induction over antirealists in the way Wray constructs the pessimistic induction over realists. Imagine that Stanford was confident that his proposal was unproblematic on the grounds that it was better than its forerunner, say, Kukla's proposal (1996). We can now see in retrospect that Stanford was wrong, i.e., that Stanford's proposal was problematic, as was its forerunner. By parity of inductive reasoning, our philosophical offspring will see that Lyons's proposal is problematic as was Stanford's proposal, although Lyons might be confident now that his proposal is unproblematic on the grounds that it is better than Stanford's proposal. It is a fallacious to reason that since an antirealist proposal is better than its predecessor, it is unproblematic unlike its predecessor.

Let me now turn to the issue of whether antirealist explanations of the success of science have been improving as scientific theories have been improving. In an earlier work, I answer this question as follows:

It is not clear, however, that there has been any improvement from van Fraassen's explanation (1980) to Stanford's explanation (2000). After all, it is neither the case that the scope of the past antirealist explanations has been increasingly widening, nor the case that the problems with the past antirealist explanations have been increasingly less serious. (Park, 2014: 19) 
So we do not even need to employ the pessimistic induction over antirealists to dampen the antirealist aspiration to attain an unproblematic antirealist explanation of the success of science. The pessimistic induction over antirealist theories alone can do the job.

Relatedly, antirealists cannot confute the pessimistic induction over antirealist theories in the way Fahrbach, Park, and Mizrahi confute the pessimistic induction over scientific theories. It is neither the case that the number of recent past antirealist theories, the ones close in time to Lyons's proposal, is greater than the number of distant past antirealist theories, nor the case that the former are unproblematic while the latter are problematic. All the antirealist proposals are more or less evenly distributed over time from van Fraassen (1980) to Lyons (2003), and all the forerunners of Lyons's proposal are problematic. So we cannot hold an optimistic view about the history of the antirealist theories of the success of science.

In order to diffuse this objection, antirealists might thoroughly examine my criticisms (2014) against the antirealist proposals with a view to demolishing them. For example, they might argue that on close examination, there is no conceptual flaw with Stanford's proposal, contrary to what Park (2003) claims, and hence that the pessimistic inductions over antirealist theories and antirealists evaporate.

Demolishing my criticisms against the antirealist proposals is a legitimate way to get around the pessimistic inductions against antirealist theories and antirealists. Keep in mind, however, that the first antirealist attempt to refute my criticisms must succeed. If it fails, that will constitute the pessimistic reason for thinking that their second attempt will also fail. The more antirealists fail, the stronger the inductive rationale will become for thinking that they will continue to fail and the more my criticisms will be fortified. It is wrong to think that science is vulnerable to a pessimistic induction but that the antirealist enterprise is not.

\section{The Pessimistic Induction over Pessimists}

This section aims to elucidate the final disastrous implication of historical optimism against pessimists. Recall that Poincaré put forward the pessimistic induction over scientific theories in 1905, predicting that then present theories would be ousted in a short time. Ernst Mach also advanced the pessimistic induction over scientific theories in the early $20^{\text {th }}$ century:

Whoever knows only one view or one form of a view does not believe that another has ever stood in its place, or that another will ever succeed it. (Mach, 1911: 17)

Based on Poincaré and Mach's mistaken views about their present theories, we can construct a pessimistic induction over pessimists, viz., since Poincaré and Mach were wrong about their present theories, subsequent pessimists are also be wrong about their present theories. Laudan and Putnam formulated the pessimistic inductions over scientific theories in the 1970s:

Most of the past theories of science are already suspected of being false; there is presumably every reason to anticipate that current theories of science will suffer a similar fate. (Laudan 1977: 126).

Just as no term used in the science of more than fifty (or whatever) years ago referred, so it will turn out that no term used now (except maybe observational terms, if there are such) refers. (Putnam, 1978: 25).

Laudan and Putnam were just as wrong about their present theories as Poincare and Mach were wrong about their present theories, given that recent past theories, such as the germ theory of diseases, the oxygen theory, the kinetic theory, and the special theory of relativity, have not yet been refuted, as historical optimists point out. It follows, as a matter of induction, 
that pessimists of the early $21^{\text {st }}$ century, such as Stanford (2006) and Wray (2013), are also wrong about our present theories. To go further, future pessimists will also be wrong about their present theories.

\section{Conclusion}

The pessimistic inductions over scientific theories, scientists, realists, antirealist theories, antirealists, and pessimists should all be taken seriously. It is wrong to think that the pessimistic inductions over scientific theories, scientists, and realists make sense but that the pessimistic inductions over antirealist theories, antirealists, and pessimists do not. There is no reason for thinking that the pessimistic specter can pervade over scientific theories, scientists, and realists, but not over antirealist theories, antirealists, and pessimists.

Antirealists and pessimists might complain that the pessimistic inductions over antirealist theories, antirealists, and pessimists are all absurd. The fact that Stanford's proposal is problematic does not constitute an inductive rationale for thinking that Lyons's proposal is problematic. It is simply fallacious reasoning that since Poincaré, Mach, Laudan, and Putnam made mistakes, subsequent pessimists also make mistakes. Past mistakes do not amount to grounds for predicting further mistakes and failures but rather amount to grounds for predicting improvement and achievement.

My rejoinder is to point out that a similar complaint can be made against the pessimistic inductions against scientific theories, scientists, and realists. Why think that the demise of past scientific theories constitutes an inductive rationale for predicting the demise of present scientific theories? Why not think that scientists' past mistakes are the means to arrive at true theories? A double standard is involved with the position that improvement and achievement ensue my mistakes whereas further mistakes and failures ensue others ' mistakes.

This paper can be summed up as follows. Antirealists have been advancing problematic proposals concerning the success of science. For this reason, we should be pessimistic about antirealists. Pessimists have been wrong about their present scientific theories for the past one hundred years or so. For this reason, we should be pessimistic about pessimists. An interesting issue for future research on this topic is whether this pessimistic induction against antirealists and pessimists is better than the no-miracles argument (Putnam, 1975; Psillos, 1999) as a positive argument for scientific realism.

\section{References}

Brown, James (1994). Smoke and Mirrors: How Science Reflects Reality. New York: Routledge.

Devitt, Michael (2011). “Are Unconceived Alternatives a Problem for Scientific Realism?”, Journal for General Philosophy of Science 42: 285-293.

Doppelt, Gerald. (2007). "Reconstructing Scientific Realism to Rebut the Pessimistic Metainduction”, Philosophy of Science 74 (1): 96-118.

Fahrbach, Ludwig (2011a). "How the Growth of Science Ends Theory Change", Synthese 180 (2): 139-155.

1283-1292.

(2011b). "Theory Change and Degrees of Success", Philosophy of Science 78 (5): 
Fine, Arthur (1986). "Unnatural Attitudes: Realist and Instrumentalist Attachments to Science", Mind 95: 149-179.

(1991). “Piecemeal Realism”, Philosophical Studies 61 (12): 79-96.

Kitcher, Philip (1993). The Advancement of Science: Science without Legend, Objectivity without Illusion. New York: Oxford University Press.

Kukla, André (1996). "Antirealist Explanations of the Success of Science", Philosophy of Science 63 (Proceedings): S298-S305.

Laudan, Larry (1977). Progress and Its Problems: Towards a Theory of Scientific Growth. California: University of California Press.

(1981). “A Confutation of Convergent Realism”, Philosophy of Science 48 (1): 1949.

(1984). "Explaining the Success of Science: Beyond Epistemic Realism and Relativism", In James Cushing, C.F. Delaney, and Gary Gutting (eds.), Science and Reality. Notre Dame: University of Notre Dame Press: 83-105.

Leplin, Jarrett (1997). A Novel Defense of Scientific Realism. New York: Oxford University Press.

Lyons, Timothy (2003). "Explaining the Success of a Scientific Theory", Philosophy of Science 70 (5): 891-901.

Mach, Ernst (1911). History and Root of the Principle of the Conservation of Energy (Jourdain P. E. B., Trans.). Chicago: Open Court Publishing Company.

Mizrahi, Moti (2013). “The Pessimistic Induction: A Bad Argument Gone Too Far", Synthese 190 (15): 3209-3226.

Musgrave, Alan (1988). "The Ultimate Argument for Scientific Realism", In Relativism and Realism in Science. Robert Nola (ed.), Dordrecht: Kluwer Academic Publishers: 229-252.

Park, Seungbae (2003). “Ontological Order in Scientific Explanation”, Philosophical Papers 32 (2): $157-170$.

(2011). "A Confutation of the Pessimistic Induction", Journal for General Philosophy of Science. 42 (1): 75-84.

-------- (2014). “A Pessimistic Induction against Scientific Antirealism”, Organon F 21 (1): $3-21$.

Poincaré, Henri (1905/1952). Science and Hypothesis. New York: Dover.

Psillos, Stathis (1999). Scientific Realism: How Science Tracks Truth. New York: Routledge. 
Putnam, Hilary (1975). Mathematics, Matter and Method (Philosophical Papers, vo. 1), Cambridge: Cambridge University Press.

(1978). Meaning and the Moral Sciences. London: Routledge \& K. Paul.

Quine, Willard V. O. (1969). "Epistemology Naturalized”, In Ontological Relativity and Other Essays. New York: Columbia University Press.

Saatsi, Juha (2009). “Grasping at Realist Straws”, Review Symposium, Metascience 18: 355362.

Stanford, P. Kyle (2000). “An Antirealist Explanation of the Success of Science”, Philosophy of Science 67 (2): 266-284.

(2006). Exceeding Our Grasp: Science, History, and the Problem of Unconceived Alternatives. Oxford: Oxford University Press.

Worrall, John (1989). "Structural Realism: The Best of Both Worlds", Dialectica 43: 99-124.

Wray, K. Brad (2013). "Pessimistic Induction and the Exponential Growth of Science Reassessed", Synthese 190 (18): 4321-4330. 